\title{
Xajooj Tun o Baile del Tun: Un registro fotográfico sobre el Rabinal Achi
}

\author{
Xajooj Tun or Dance of the Tun: \\ A photographic record on the Rabinal Achi
}

Santiago Albert

Autor independiente

*Autor a quien se dirige la correspondencia: santiagoalbert@me.com

página web: www.santiagoalbert.com

\begin{abstract}
" $i$ Voy a hacerte entrar frente a mi eminencia, al interior de la gran fortaleza, al interior de la gran muralla;" Relación de Rabinal Achi para K'iche Achi.
\end{abstract}

\section{Presentación por Alfonso Arrivillaga-Cortés}

Vale la pena unas líneas introductorias sobre la historia de la fotografía en Guatemala para una justa dimensión del trabajo de Santiago Albert Pons. Tan larga como la historia de este arte, es la data de son los registros de daguerrotipo y fotográficos en el país. Ya en 1839, el belga León de Pontelle llevó un registro de su paso por el país, y luego en 1846, Emilio Herbruger (padre) instaló su estudio fotográfico, que conocerá como "La Imperial" (Luján, 1976; 1984:15-16) y dio inicio los retratos de sociedad. Más allá de la segunda mitad del siglo XIX, continúan arribando extranjeros que también desarrollan este invento, que cada vez ganaba más adeptos. Los retratos del japones Juan José Yas (Luján, 1982; Yas \& Noriega, 1990) y del el suizo Emilio Eichenberger, los registros atraídos por la arqueología y la naturaleza de Desiré Charnay, Osbert Salvin, Eadweard Muybridge, William T. Brigham, y Ann y Alfred Maudslay forman parte de este listado de actores de esta historia. Entre los nacionales se deben referir a Doroteo González, José Lara Corzo, Mariano González, Viviano Salvatierra, y Alberto Valdevellano (Luján, 1987, p. 3).

Ya con anterioridad Stöckli y Arrivillaga (2006) realizan un análisis de papel de los etnógrafos alemanes en este arte, encaminado además a una intencionalidad distinta a los referidos arriba, en tanto ahora es el registro de las costumbres y tradiciones indígenas, así como de las evidencias arqueólogicas y de la cultura material, el eje vertebral de este trabajo. Con una mirada si queremos más local, emic, he intentado explicar el trabajo de fotógrafos como Victor M. Vadillo, retratistas de una sociedad, en este caso de la petenera, pero que a su vez, buscaron del mismo modo salir al registro, a la salvaguarda, a la constitución de un legado, en tanto lectura de ese pasado, para las generaciones presentes (Shaw \& Arrivillaga, 2018).

A partir de la segunda mitad del siglo XX, el que por cierto hoy puede ser considerado el siglo de las aceleraciones, trajo entre otros elementos el abaratamiento de los aparatos fotográficos y de los procesos de revelado e impresión y con ello, aquellos que eran albunes de familia para unos cuantos, paso a ser mas popular y al alcance de grupos mayores. Junto con esta facilidad el país continuo siendo retratado en sus diversas dimensiones, nacionales y extranjeros, plamaron el país en plata sobre gelatina y dentro de este movimiento que resultó verdadermente revolucionario surgieron figuras como Luis Gonzalez Palma, que continuó en esa búsqueda, llevando ahora a la fotografía al campo de la intervención performativa.

Desde finales del siglo pasado y entrado el presente, siendo el país residencia de un importante número de fotógrafos nacionales y extranjeros que se instala uno más, Santiago Albert, que debía marcar un paso y 
una búsqueda distinta para colocarse en este listado de autores con un distinción y una preocupacion especial, la captura de las piezas maestras de la humanidad y con ello una misión que pareciera imposible, capturar lo intangible.

Sobre la obra de Santiago Albert acerca del Rabinal Achi

Perseguir los acervos de las tradiciones, introducirse al mundo de lo sagrado, sumergirse en lo mitológico, atrapar lo intangible, vaya tareas intrincadas de enorme complejidad, que conllevan la busqueda de un buen retrato, una fotografía que pueda decir más allá de lo que las palabras no alcanzaron, incluso, ni a sugerir. Es la puesta en escena que deriva del halo, es aura, umbral que navega entre dos universos, frontera que viene de lo material y transita a lo intangible. Para el gozo de la vista de nosotros, pasmados ante el prisma de luces y grises, atraídos como imanes esta vez en empatía visual que crea sensaciones, acaso la ruta de inmaterial, sea el hagase, sonido, calor, sensación, color... una captura que es resultado de un trabajo, largo profundo, una construcción de eventos que suman cual trama la puesta en escena.

La magia del hecho cultural, la transformación, el hágase la magia. Este reto se ha logrado gracias al concurso de Santiago Albert Pons y para muestra serie de una pieza icono, el Rabinal Achi, seguramente conocido desde sus inicios como xajooj tun, el baile del tun, una de las representaciones danzarias mitológicas de la hija del señor, los rabinaleb. Como bien nos advierte este maestro del lente, es el sumergirse en la vispera, el codo a codo con los danzantes, sostenedores de tradición, la contruccion de una relacion que permite ver y ser visto al lente sin aquella tensión de una captura foránea. Y claro todo imprescindible para ingresar en la esfera previa a la presentación, al espectador; a la invocación, el traer a la tierra, a los trajes y mascaras y finalmente a los danzantes siglos de persistencia a la que ellos se encadenan.

\section{Xajooj Tun}

Todo parece indicar que los bailes del tun, xajooj tun, son una variante extendida a lo largo de la región de la Baja Verapaz y vecindades, de la guacamaya, del tzunum, patzka, zacatun', entre otros son una muestra de esta expresión que a pesar, junto con otras piezas del arte indigena, de ser prohibidas y perseguidas continúan hasta el día de hoy resistiendo. En el caso particular que nos atrae, trata de un evento sucedido a la altura del postclásico (siglo XV) cuando resulta una incisión política achi de los k'iches, representada en este drama por los dos opuestos, Kiche'Achi y Rabinal Achi, este último procesado por intento de rapto de un rabinaleb. Por su puesto, paralelo a esta historia dinástica, se desarrolla cargada de múltiples siginificados por sus personajes un universo mítico que como es común en la cosmovisión maya, mito e historia suelen fundirse, arrancar tan unidas que la disección una de otra resulta practicamente imposible.

Varios son los personajes que han colaborado con esta tarea de permanencia. Citaremos solo dos, el holpop Bartolo Sis que en el año de 1850, transcribiera el drama que luego llamo la atencion el abate Charles-Étienne Brasseur de Bourbourg, para quien se realizó la primera presentación para un occidental, aquel 25 de enero de 1856, día de la Conversión de San Pablo. De algo podrán estar tranquilos hasta ahora, Brasseur de Bourbourg y Bartolo Sis, aquella permanencia que tanto preocupaba y que tantos eventos a sorteado, a uno cuanto tunes del oxlaju baktun, permanece.

Quizá en resonancia con el carácter denotativo que símbolos y sentidos tiene entre los mayas, y siendo el Rabinal Achi, junto con otros bailes del tun, un símbolo de la resistencia por su propia permanencia, a juzgar por el sentido crítico de varios de los artículos de este número, diriamos que a pesar de la declaratoria de la Unesco, ahora recibiendo como danzante que va a zapatear junto con ellos, José León Coloch (vease García-Escobar, 2015, p. 129) ingresa como cuidador de aquella tradición de la que fue cargador por varios años. Se trata de una tarea que tomará de su suegro Esteban Xolop, y este de su abuelo, y el abuelo del suyo, en una línea de sucesión que pasó hacia atrás por el holpop Bartolo Sis, y hoy renovada por el Oxlaju Baktun. Quince fotografías, en su mayoría de los rezos y velaciones invocatorias, la víspera, manifiesto tangible, en tanto sabemos que nos conduce aun desconociendo a donde rezos, y más velas, luces, máscaras, aperos, hachas rompedoras de las nubes, invocaciones en dirección al tiempo sagrado, el arribo de los ancestros que ocupan a los danzantes para bailar, todo un universo al que ingresan y junto con ellos Santiago Albert Pons para atrapar más allá del evento.

\section{Referencias}

Brasseur, C. É. (1862). Rabinal-Achí ou le drame-ballet du Tun. En Collection de documents dans les langues indigènes, pour servir à l'étude de l'his- 
toire et la philologie de l'Amérique ancienne... 2/2a parte. Paris: Arthus Bertrand \& Auguste Durand.

Garcia-Escobar, C. R. (2015). José León Coloch. El Quiché Achí del Baile del Tun. En Ciencias Sociales y Humanidades 2(2), 129-130.

Luján, L. (1976). Apuntes para la fotografía en Guatemala en el siglo XIX: Eadweard Muybridge en Guatemala 1875. Guatemala: Instituto de Antropología e Historia e Instituto Guatemalteco Americano.

Luján, Luis. (1982). Apuntes sobre la fotografía en Guatemala: Juan J. Yas y Domingo Noriega. En Exposición homenaje a J.J. Yas \& J.D. Noriega. Guatemala: Instituto de Antropología e Historia de Guatemala, Centro de Investigaciones de Mesomérica.

Luján, L. (1984). Fotografías de Eduardo Santiago Muybridge en Guatemala (1875). Guatemala: Centro Nacional de Libros de Texto, Ministerio de Educación,

Luján, L. (1987). Los indígenas de Guatemala vistos por el fotógrafo Alberto G. Valdevellano (18611928). Guatemala: Academia de Geografía e Historia de Guatemala, Centro de Investigaciones de Mesomérica, Instituto Guatemalteco de Turismo.

Shaw, S. \& Arrivillaga, A. (2018). La Colección Fotográfica de Victor M. Vadillo. Una mirada al Petén del siglo XX. En Ciencias Sociales y Humanidades, 5 (1), 131-149.

Stöckli, M. \& Arrivillaga, A. (2006). Una nota sobre las fotografías y el registro documental. Tradiciones de Guatemala No. 66 Etnomusicología en Guatemala, 171-174.

Yas, J. J. \& Noriega J. D. (1990). La Antigua Guatemala. Buenos Aires: La Azotea. 
Xajooj Tun o Baile del Tun:

Un registro fotográfico sobre el Rabinal Achi

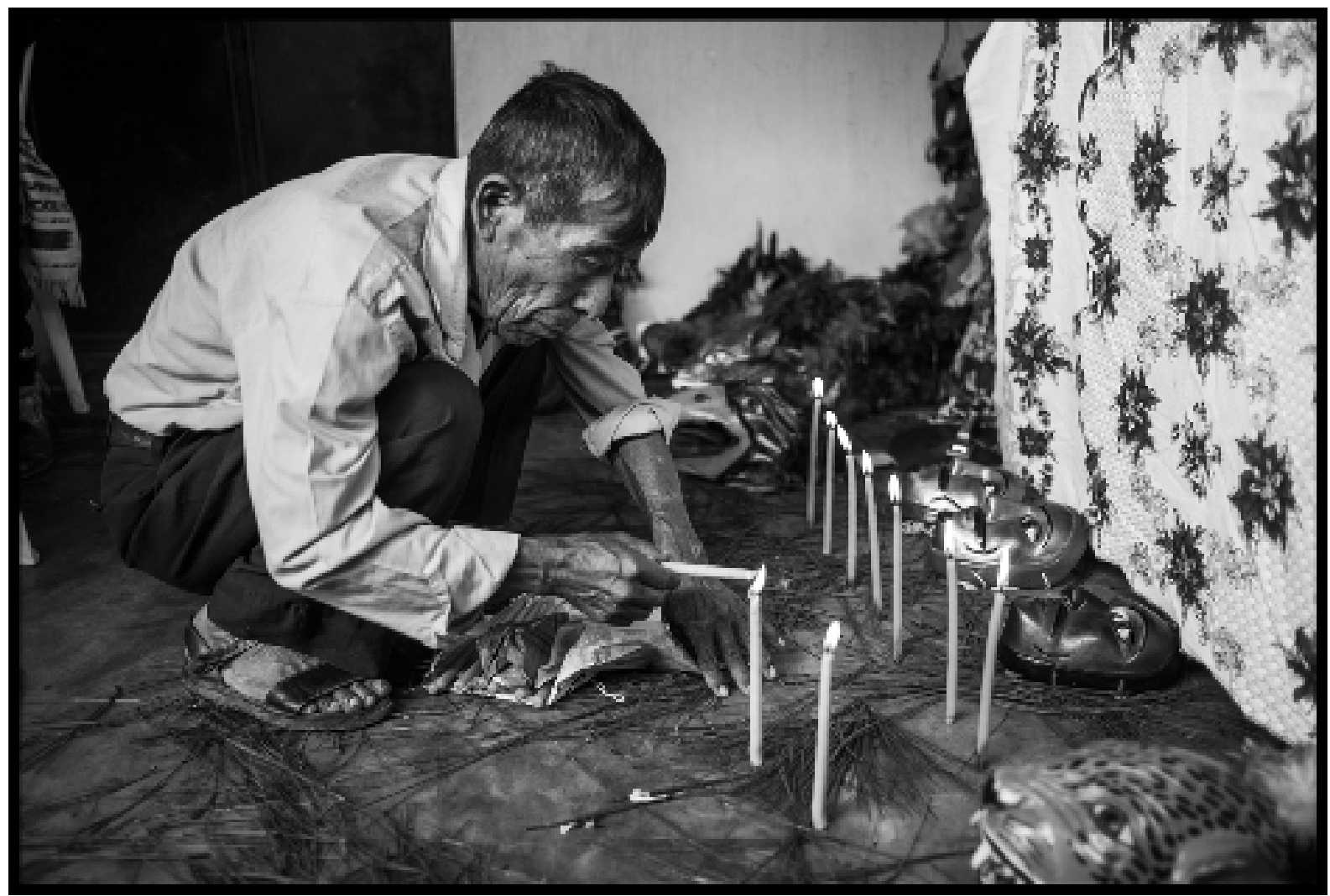

Figura 1. Encendiendo las velas, dando inicio la invocación...(fotografía S. Albert).

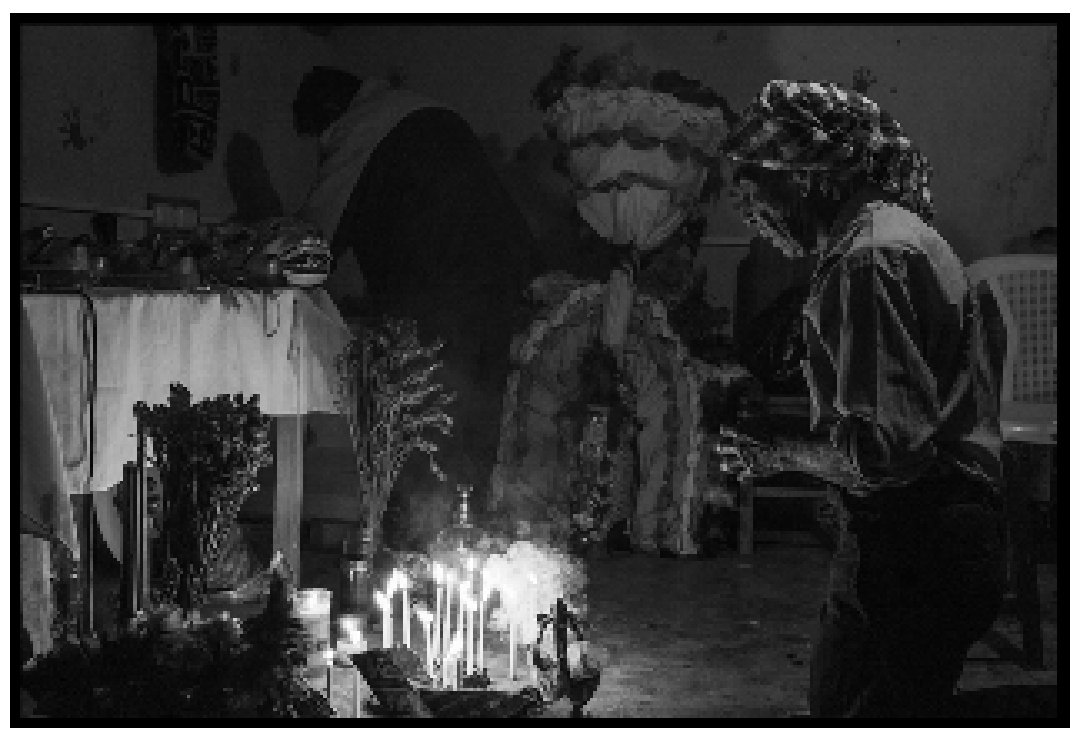

Figura 2. Dan inicio las palabras sagradas, entre humo-umbral (fotografía S. Albert). 


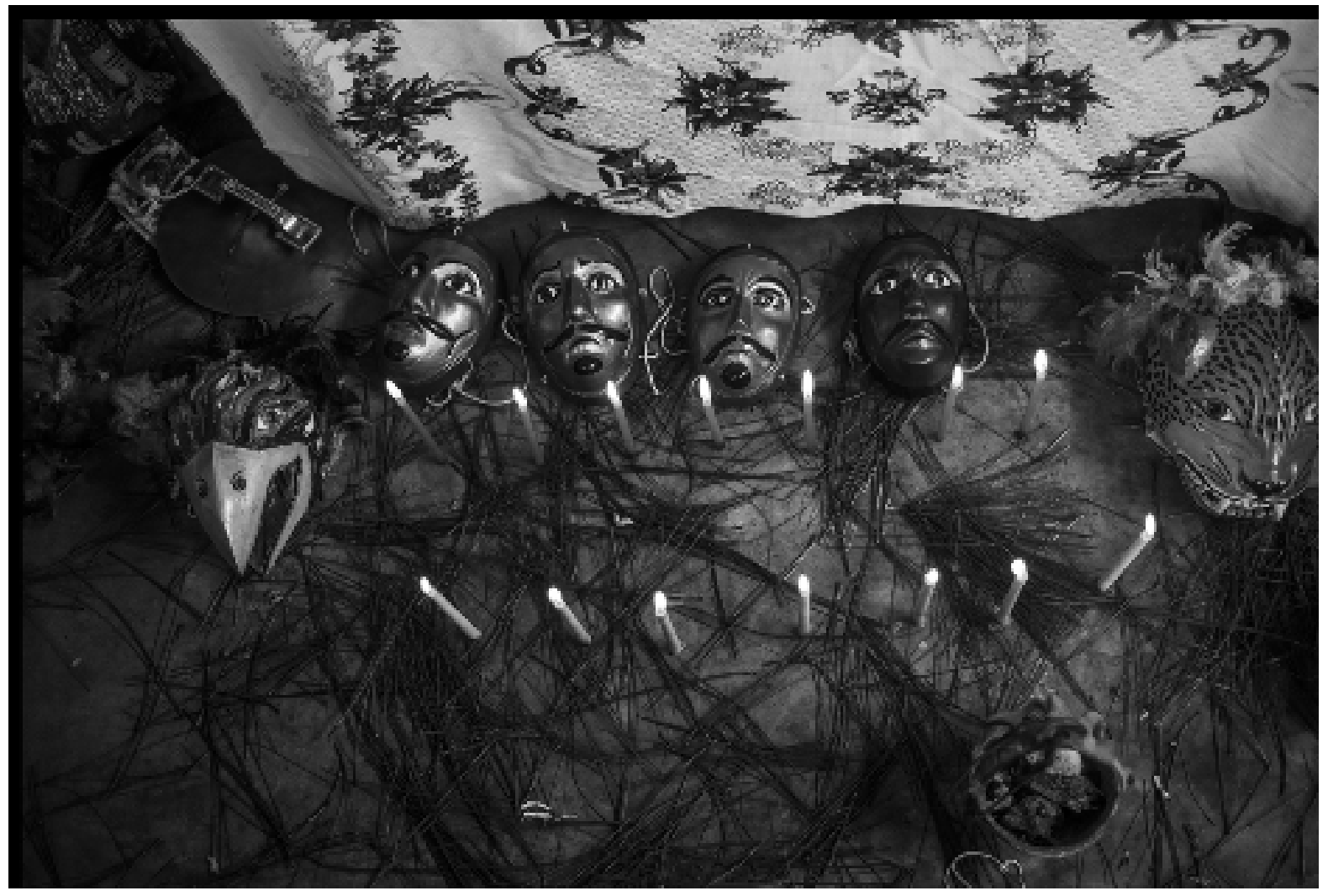

Figura 3. Guerrero Doce Águilas, guerrero Doce Tigre, Job Toj, Kiche’Achi’... cobrarán vida (fotografía S. Albert).

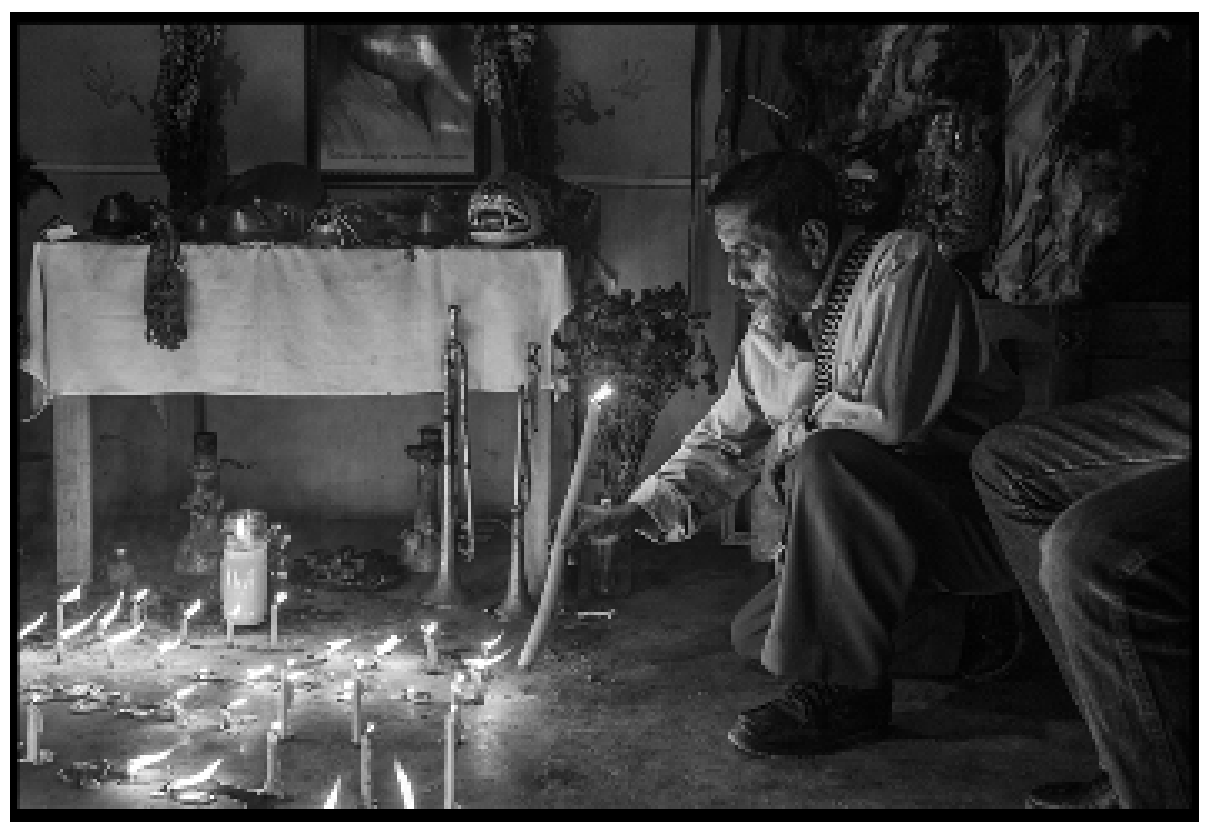

Figura 4. Tun(kul), tun (trompeta): tun (tiempo), tun (espacio) (fotografía S. Albert). 


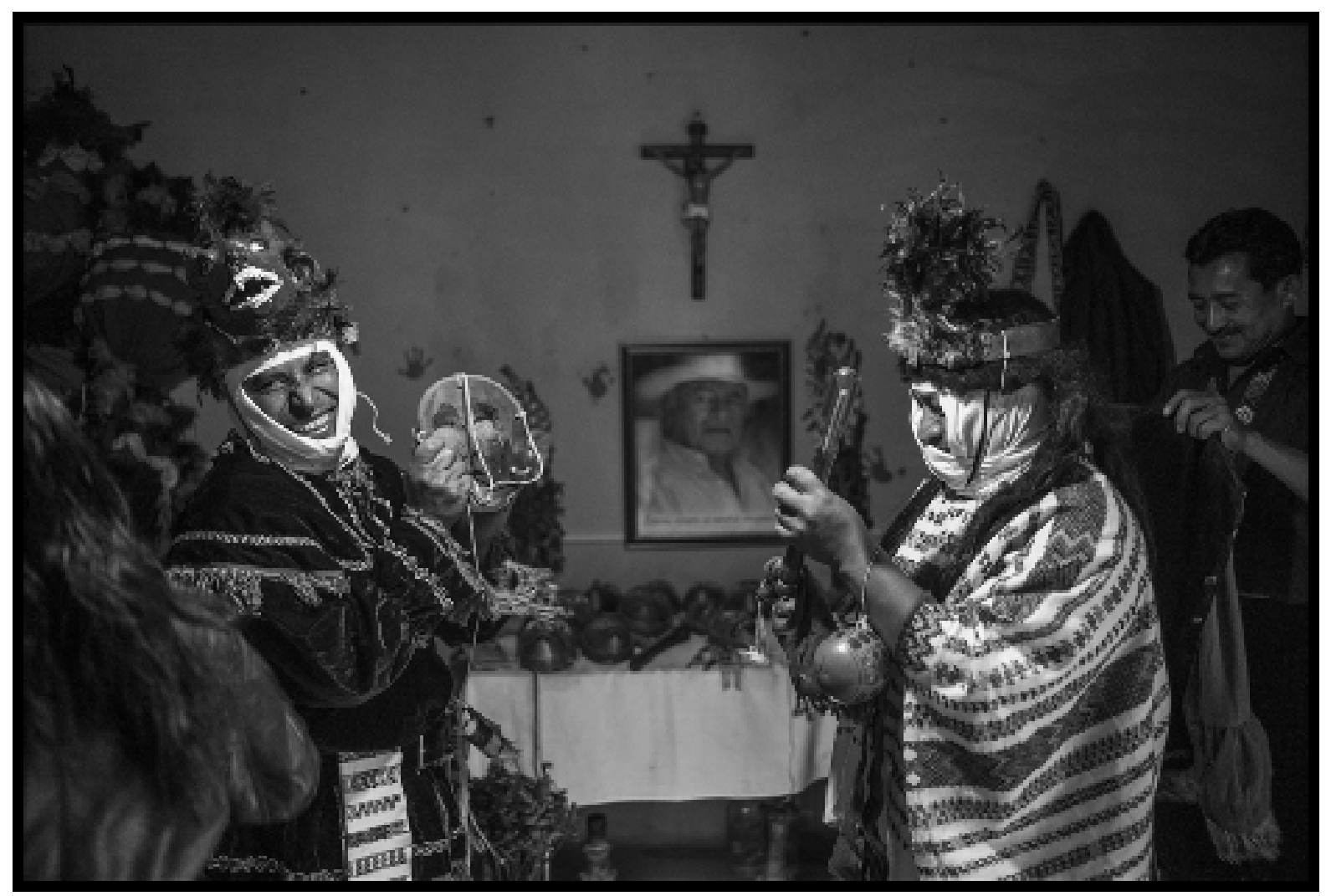

Figura 5. Vamos cobrando vida, risas de ánima, José León Coloch observa (fotografía S. Albert).

Figura 6. Hacha, trueno, obsidiana (fotografía S. Albert).

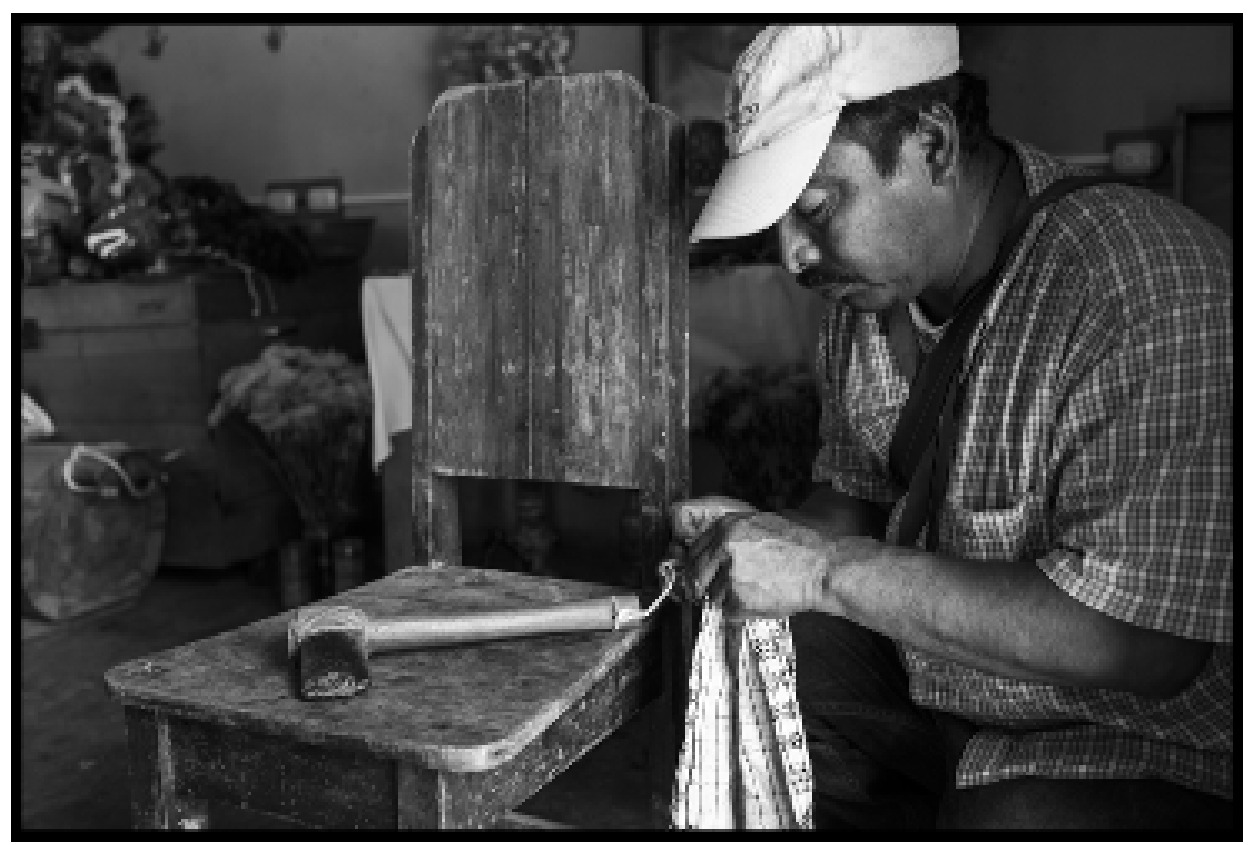

Ciencias Sociales y Humanidades, 6(1) 2019, 135-149 


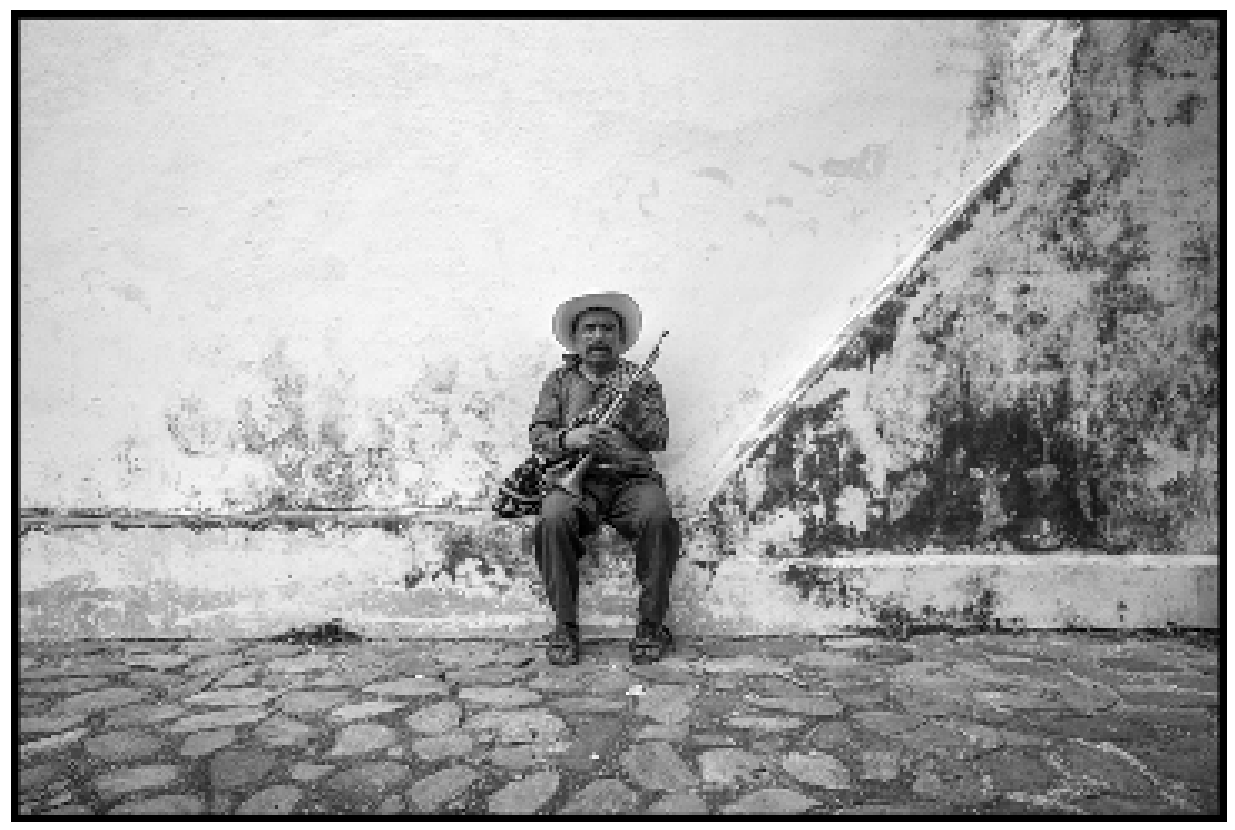

Figura 7. Tun, trompeta (fotografía S. Albert)

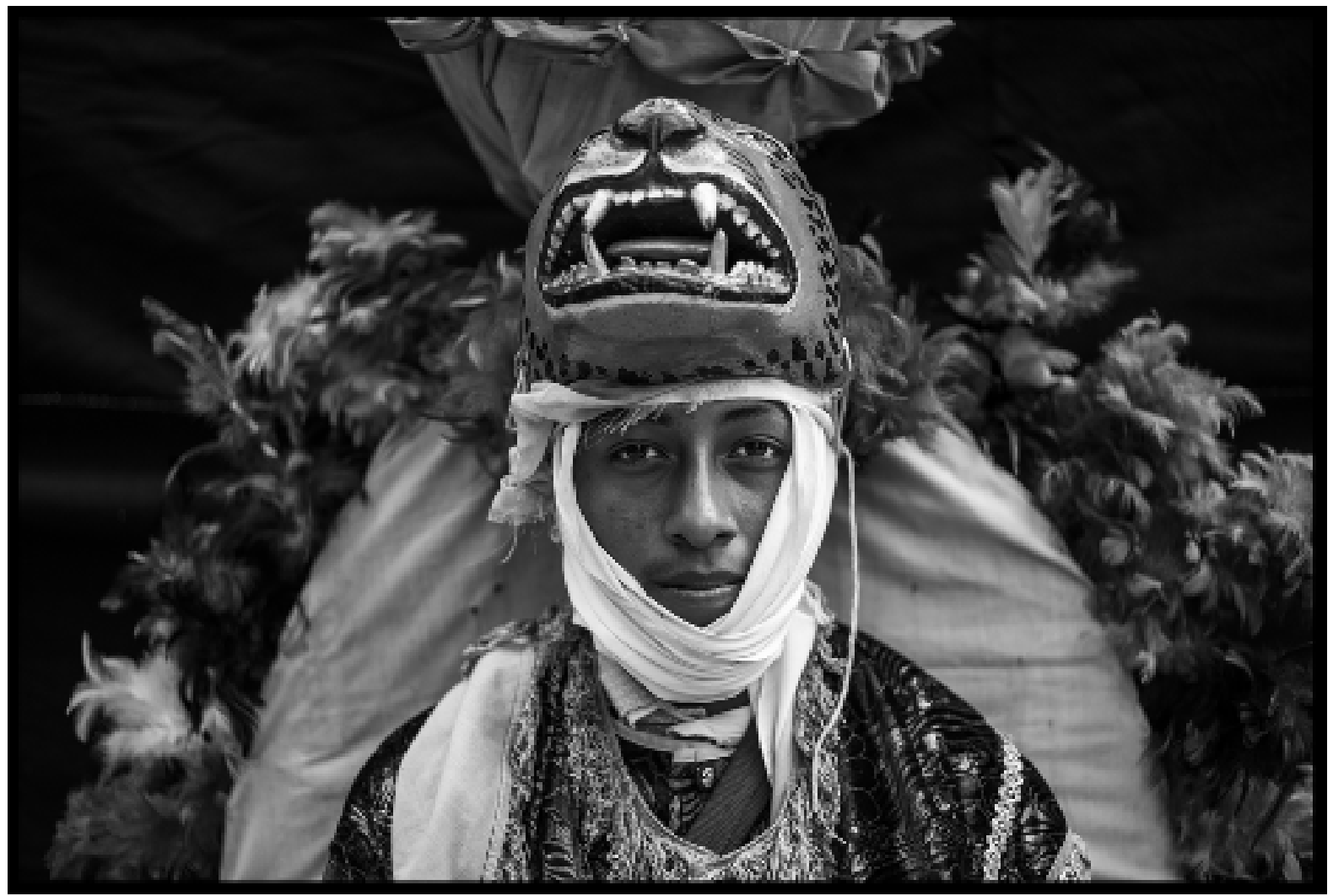

Figura 8. Entrando, al tiempo... (fotografía S. Albert). 


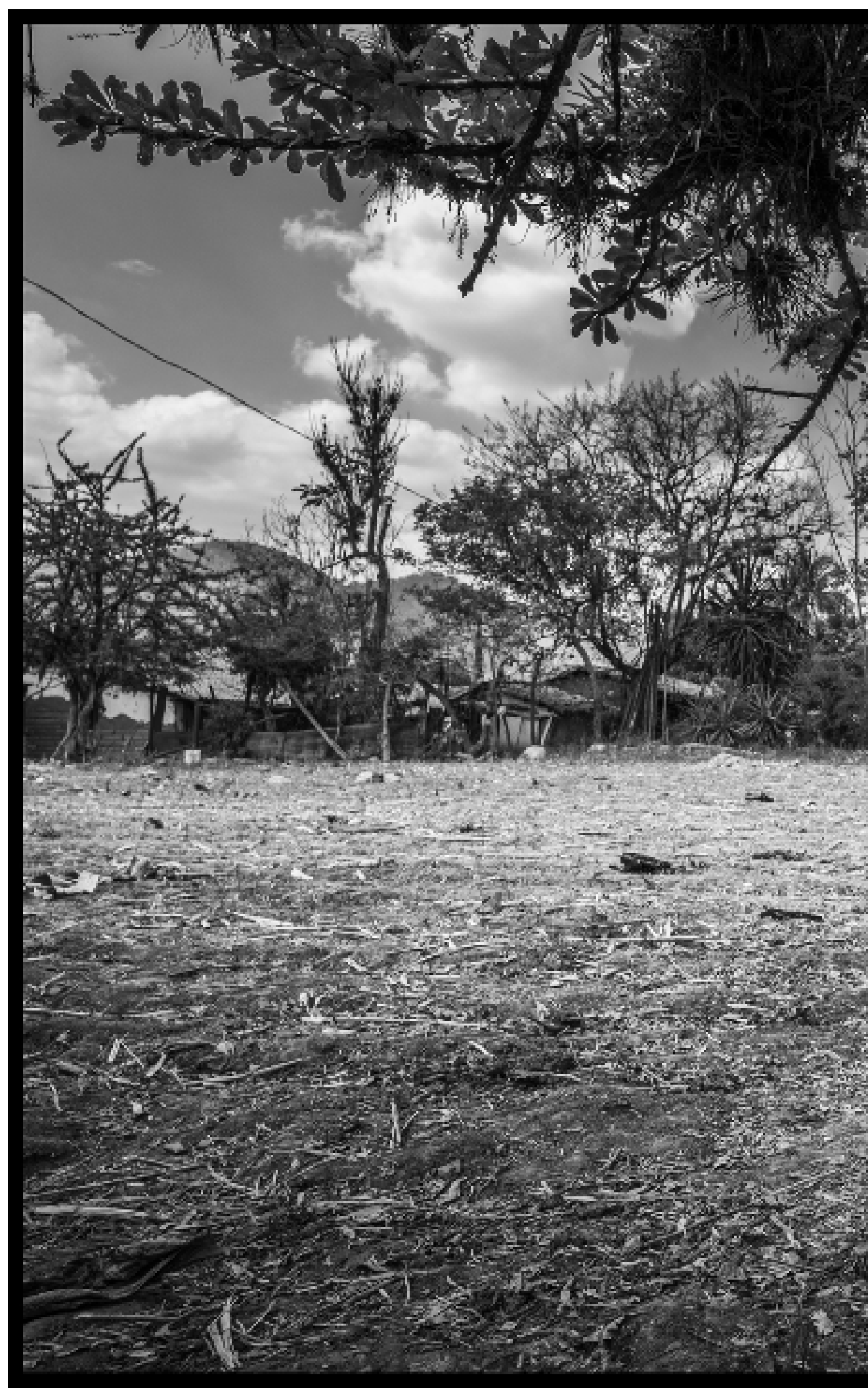

Figura 10. Dualidad (fotografía S. Albert). 


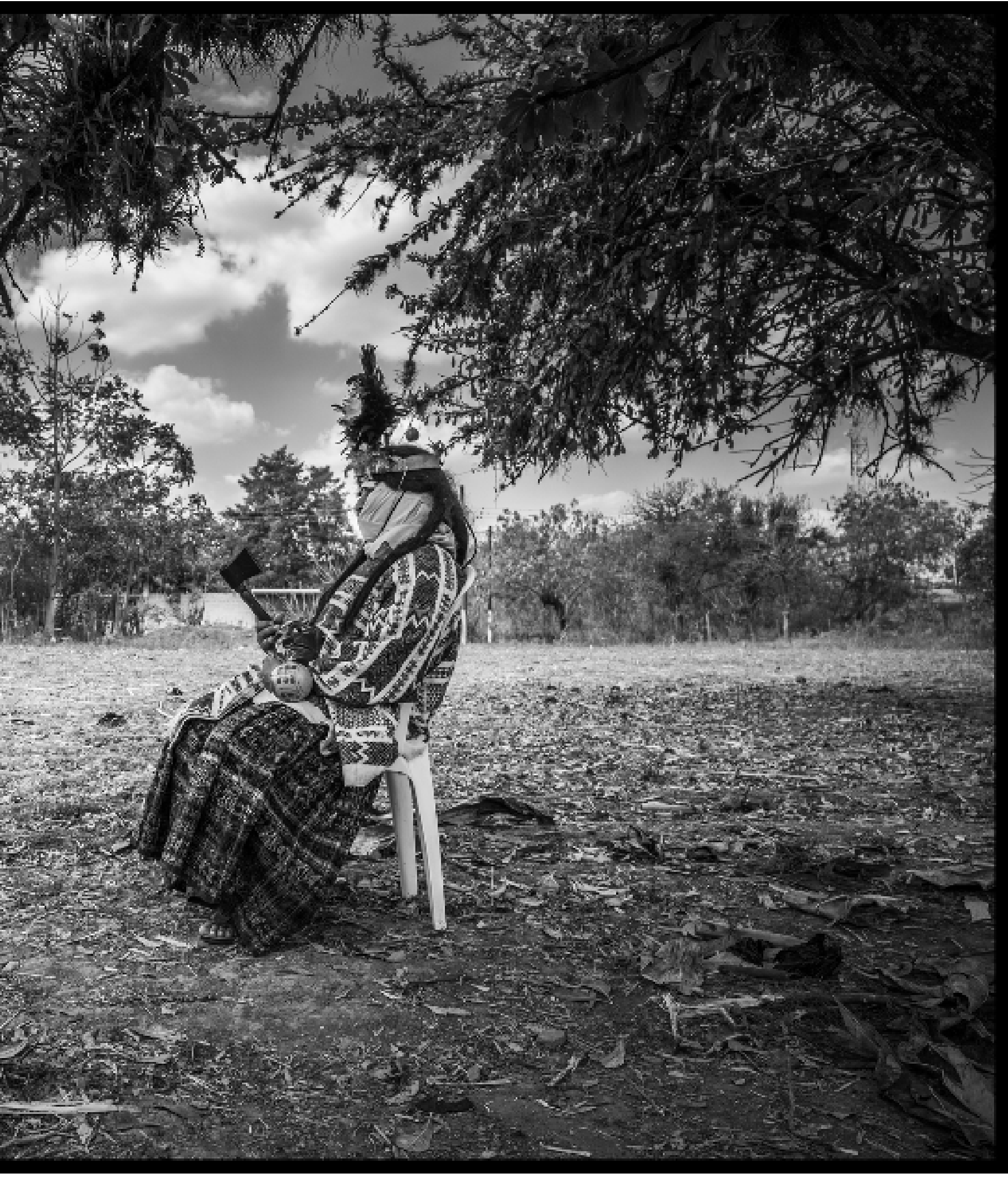


Figura 11. Por ahora seré Doce Tigre. (fotografía S. Albert).

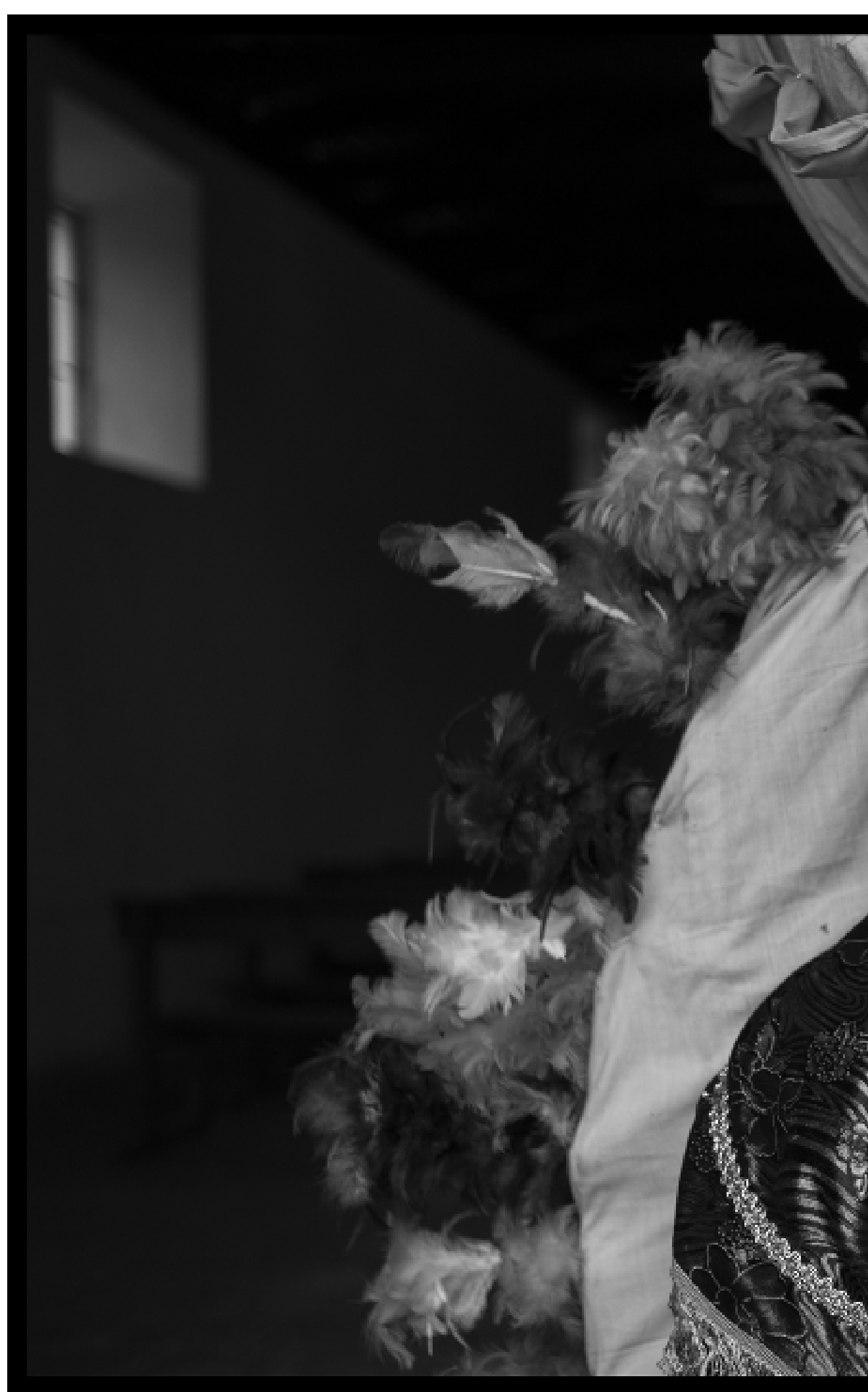




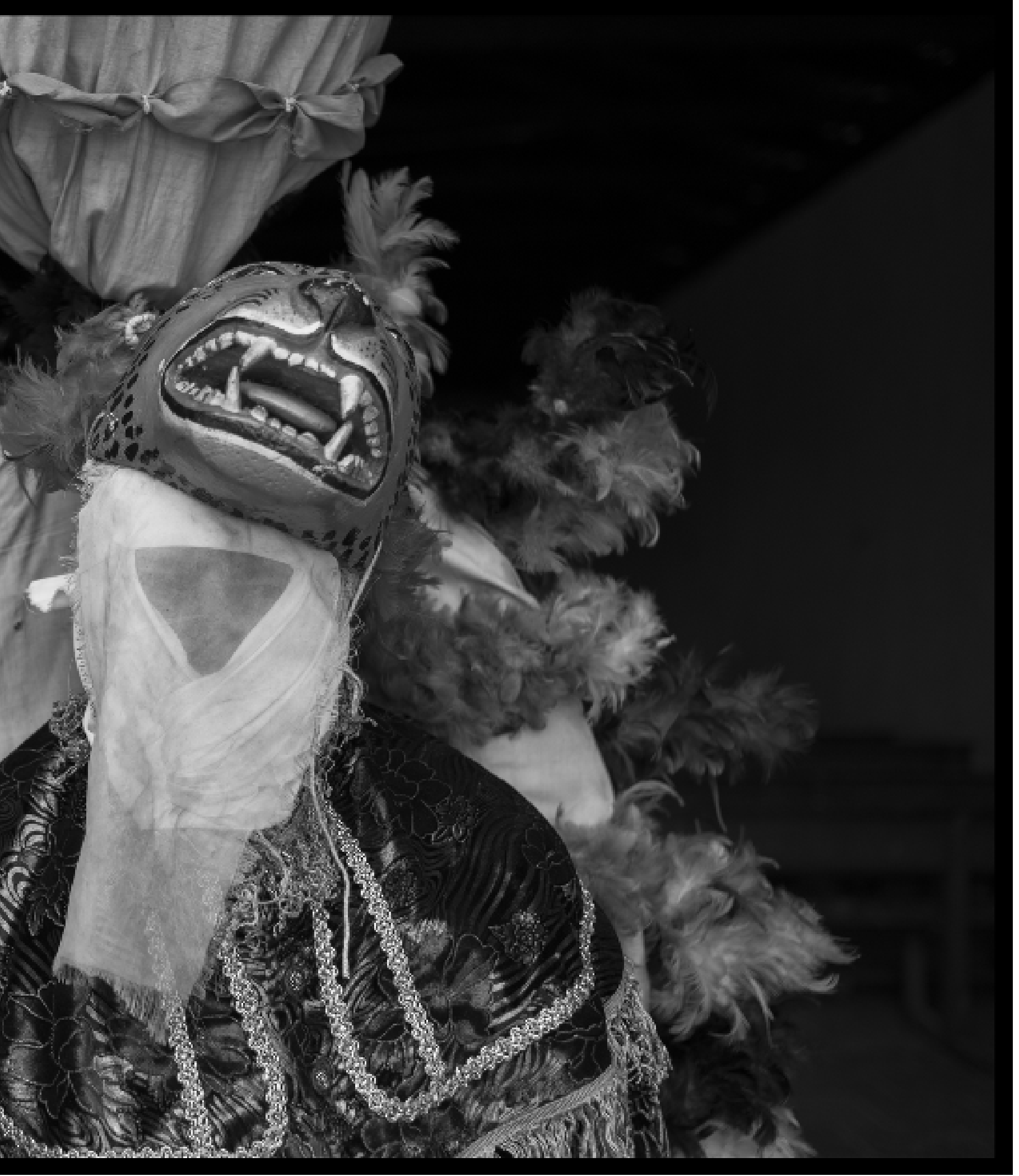




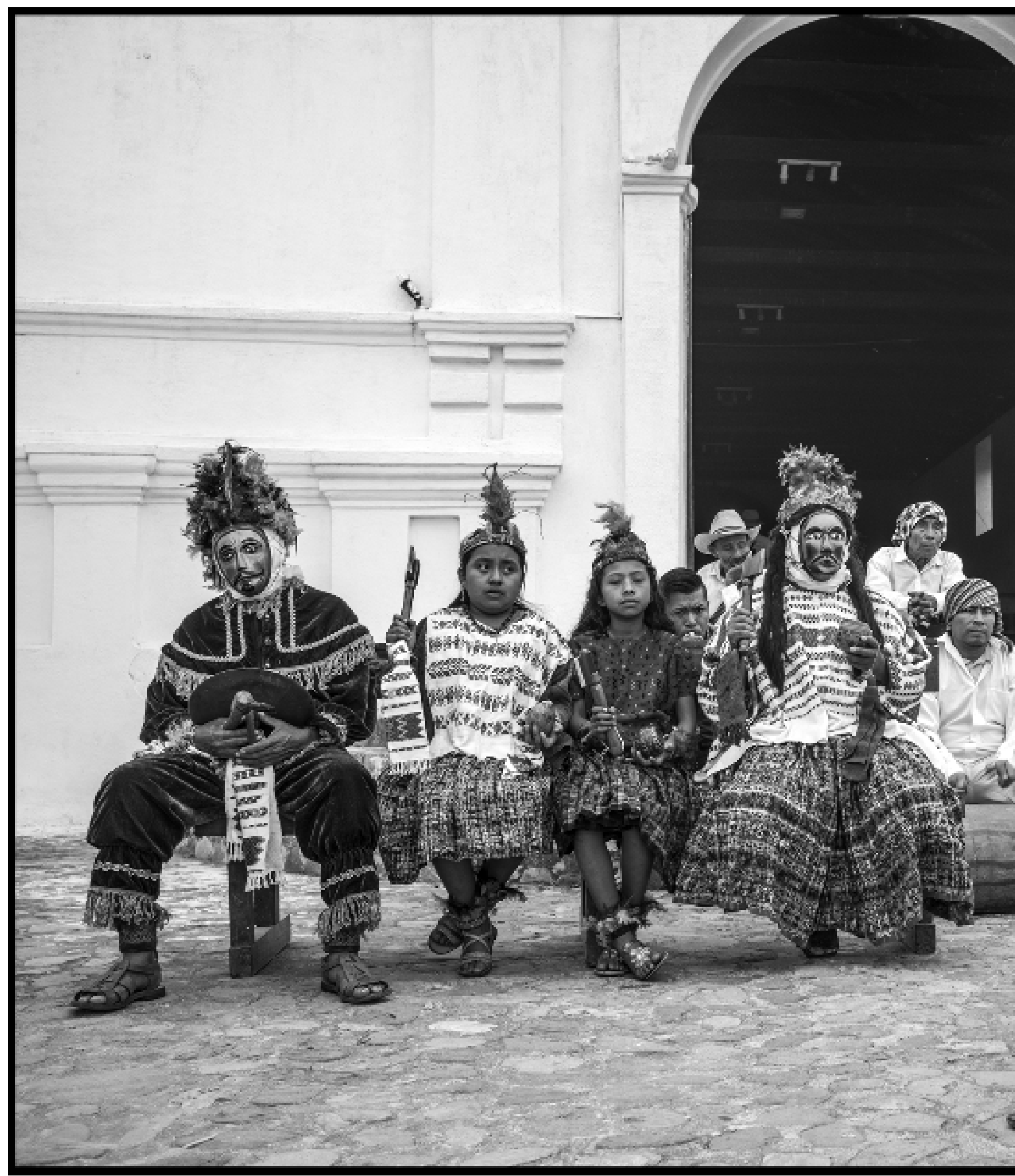




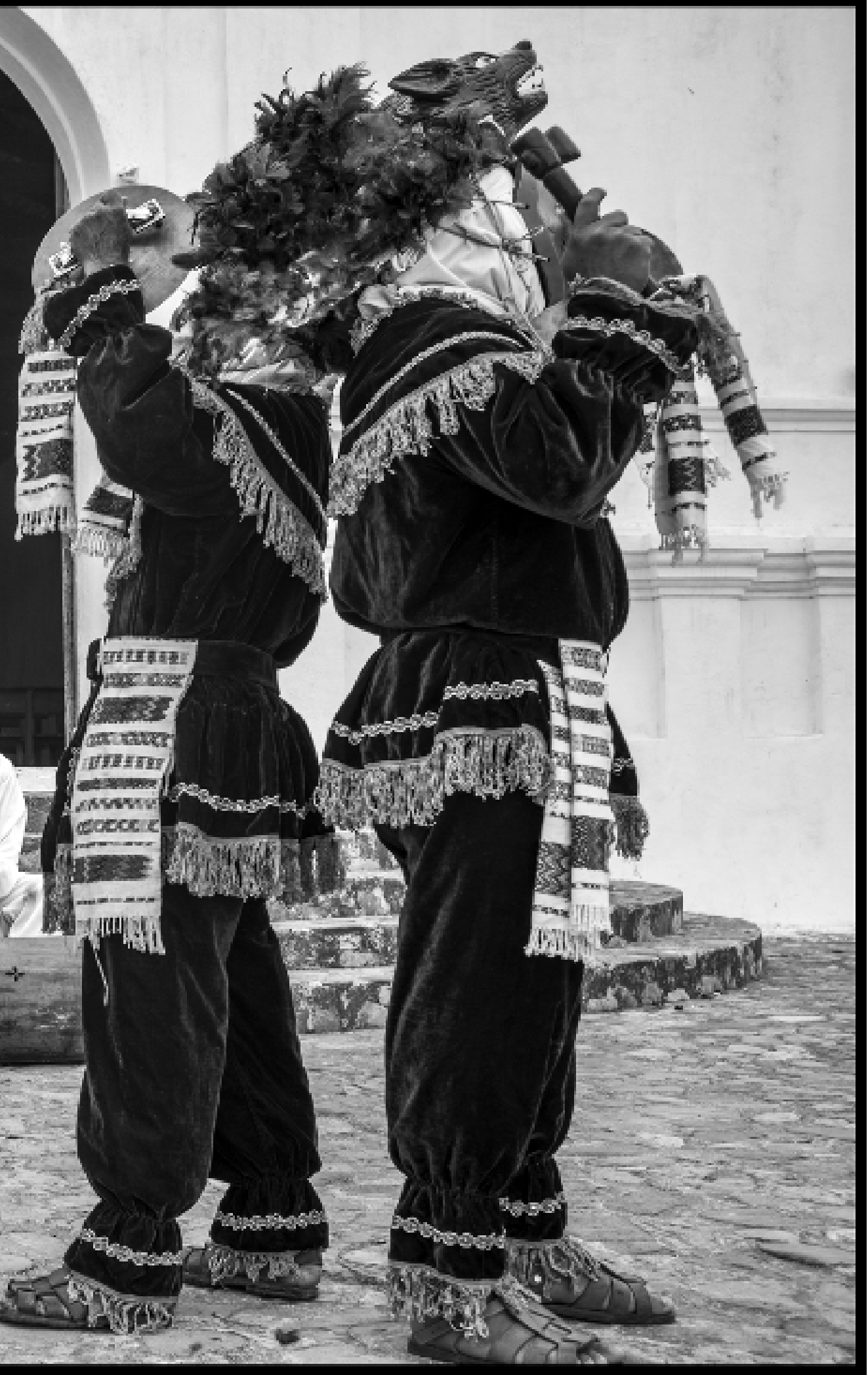

Figura 12. Guerrero Doce Tigre, Doce Águila, brota de la tierra canto fecundo (fotografía S. Albert). 


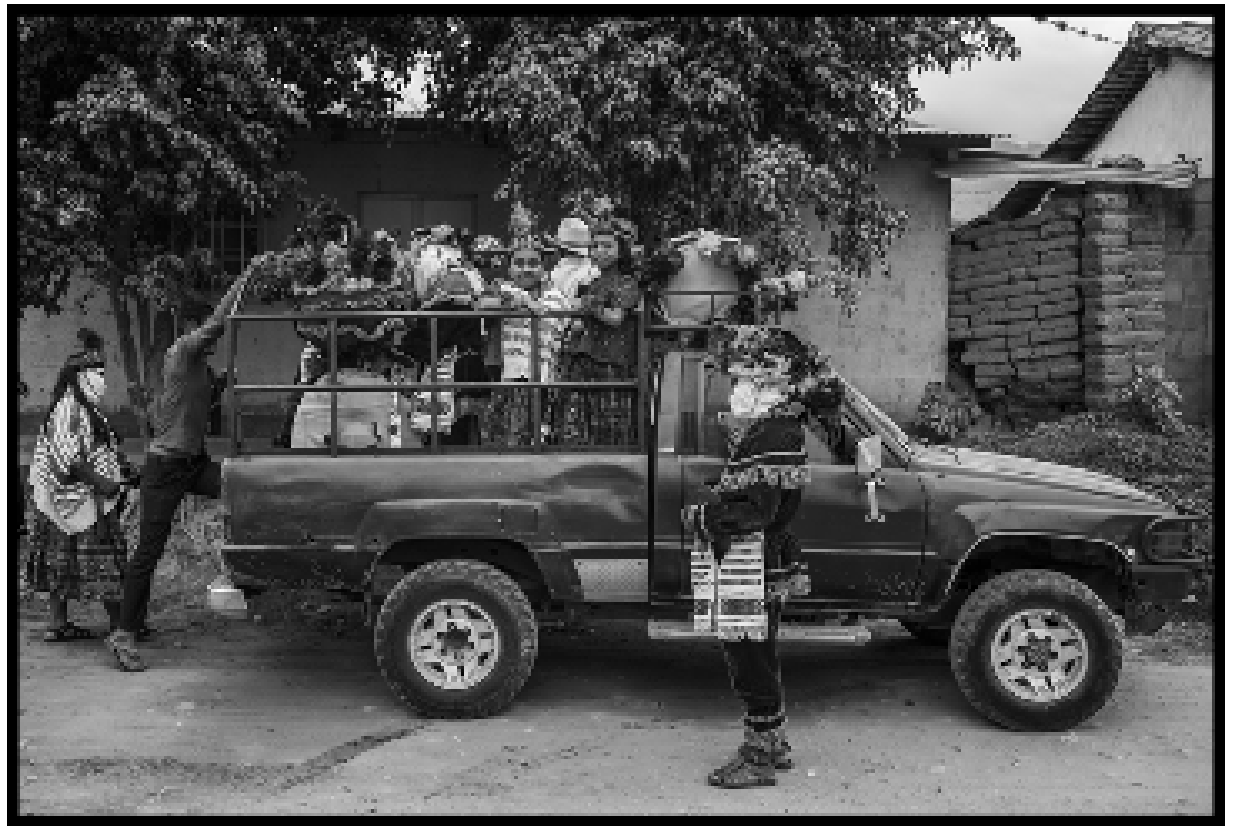

Figura 9. De camino al atrio (fotografía S. Albert).

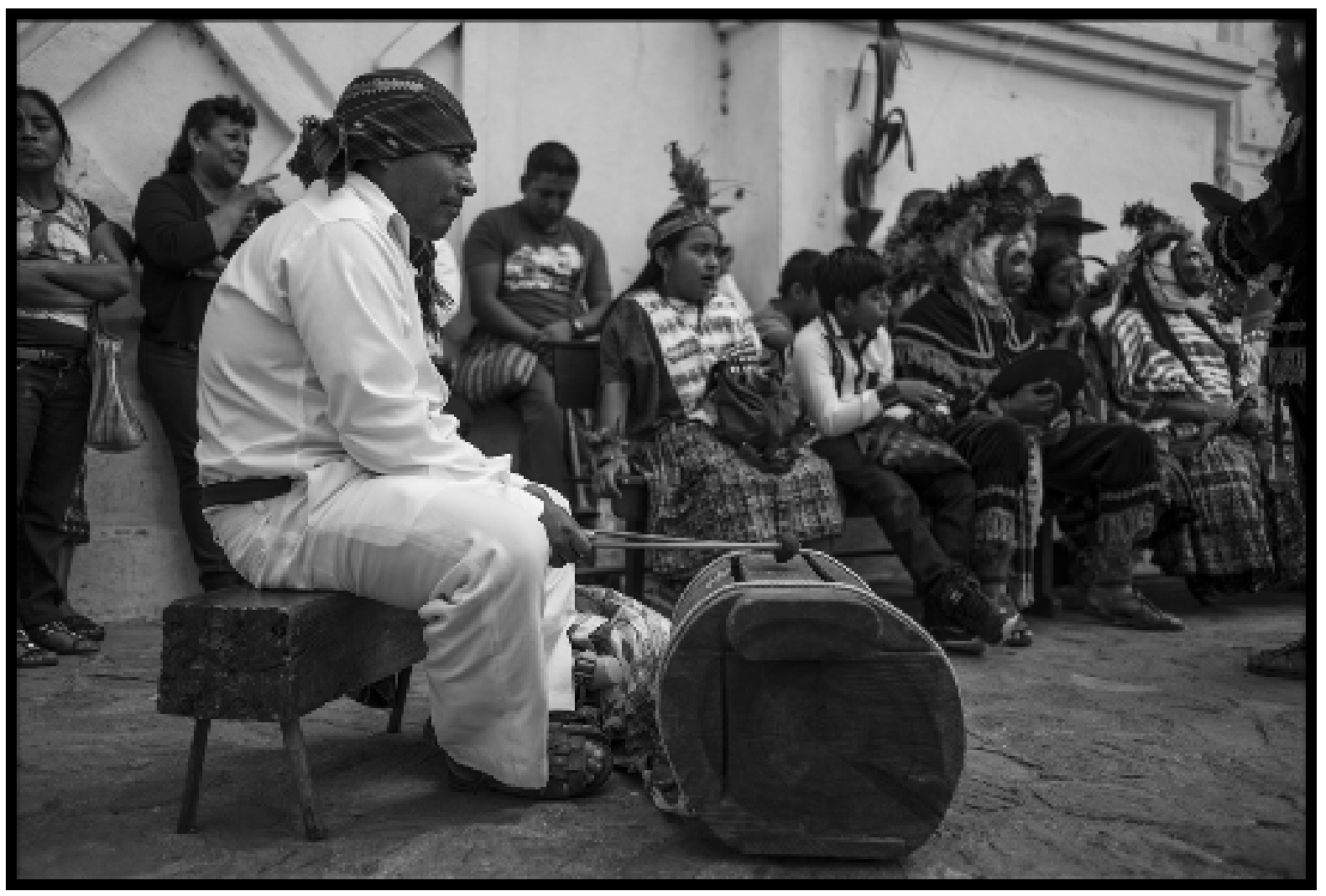

Figura 13. Preparado, una vez más, resistencia, xajooj tun (fotografía S. Albert). 


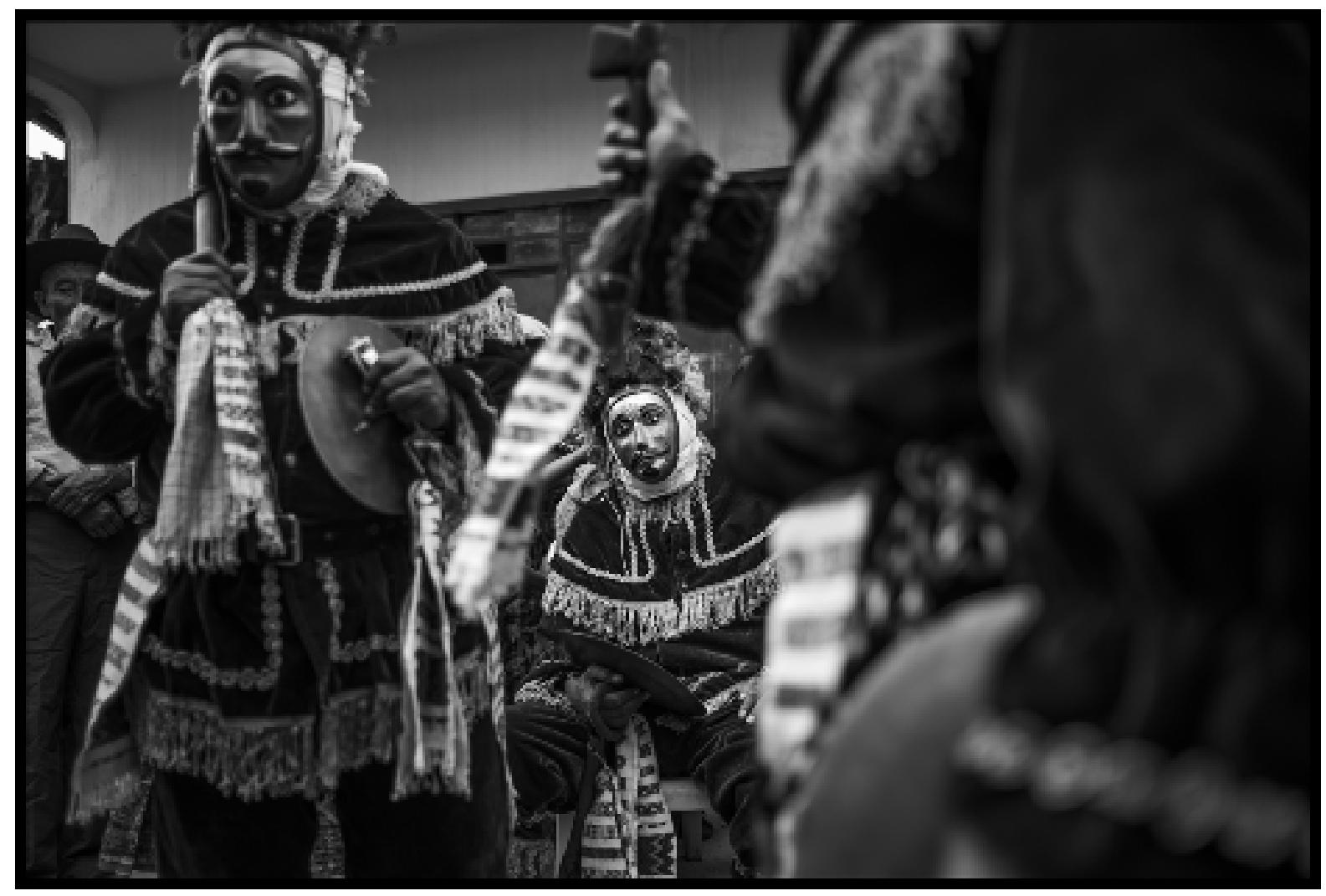

Figura 14 Xajooj (fotografía S. Albert).

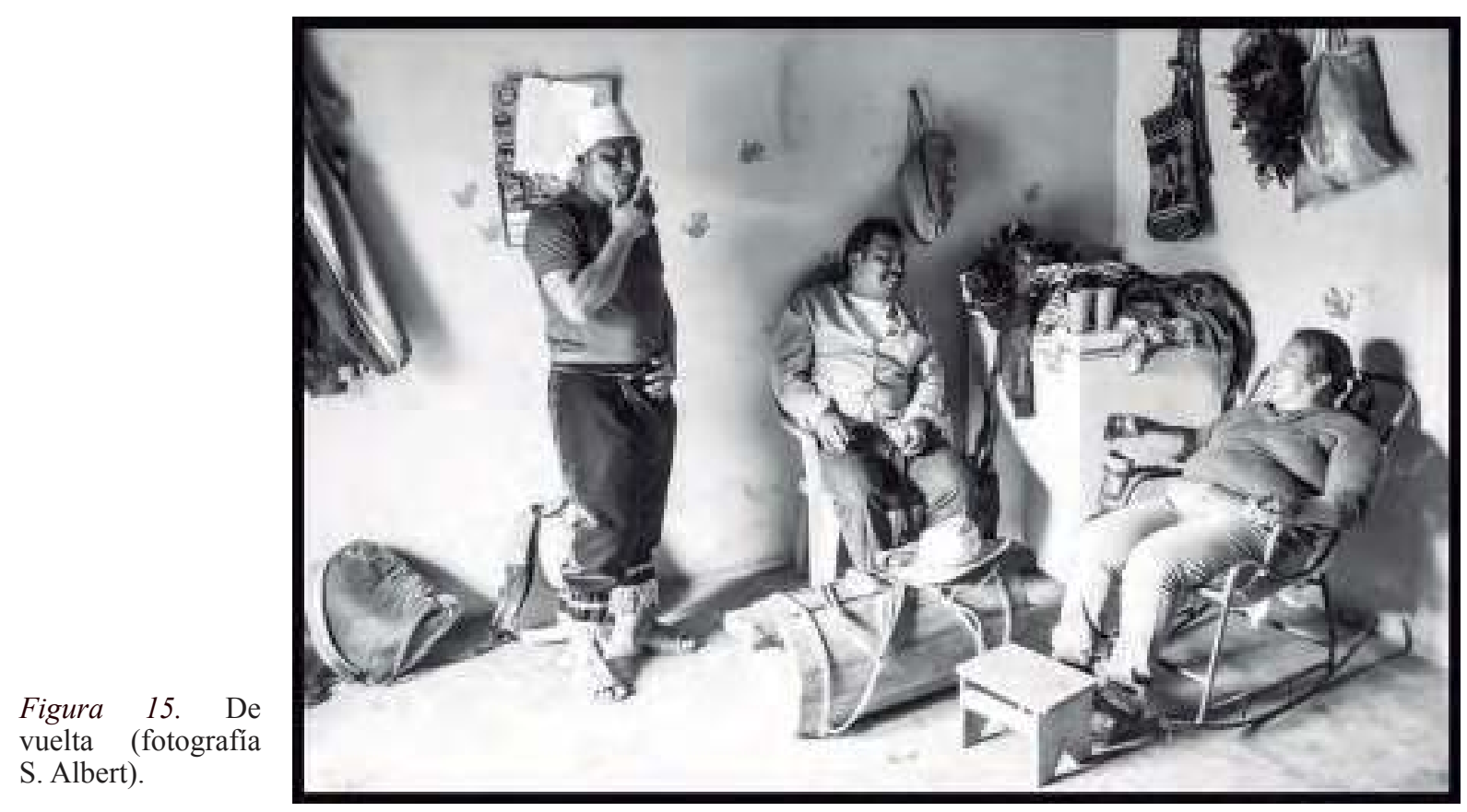

